\title{
EL CONCEPTO Y EFECTOS DE LOS TRATADOS DE PROTECCIÓN DE INTERESES GENERALES DE LA COMUNIDAD INTERNACIONAL *
}

\author{
Ángel J. RODRIGO \\ Marta ABEgón
}

SUMARIO: 1. INTRODUCCIÓN.-2. LA NOCIÓN DE TRATADOS DE PROTECCIÓN DE INTERESES GENERALES DE LA COMUNIDAD INTERNACIONAL.-3. LAS CARACTERÍSTICAS DE LOS TRATADOS DE PROTECCIÓN DE INTERESES GENERALES.-3.1. El objeto y fin: la protección de intereses generales de la comunidad internacional.-3.2. La estructura integral de algunas de sus obligaciones.-3.3. La vocación de universalidad.-3.3.1. La flexibilización en la participación y la apertura de los tratados.-3.3.2. La contribución a la creación de normas jurídicas de alcance universal.-3.3.3. La ampliación subjetiva y territorial de sus efectos.-4. LOS EFECTOS DE LOS TRATADOS DE PROTECCIÓN DE INTERESES GENERALES EN LA EVOLUCIÓN Y FLEXIBILIZACIÓN DEL DERECHO DE LOS TRATADOS.-4.1. La democratización en el proceso de elaboración y adopción de los tratados.-4.2. La erosión del papel del consentimiento.- 4.3. La capacidad de adaptación al cambio a través de la creación de regímenes internacionales generales.-5. CONSIDERACIONES FINALES.

\section{INTRODUCCIÓN}

La comunidad internacional ha evolucionado desde sus orígenes y se ha convertido en una comunidad social, política y jurídica a la vez. Estamos ante una comunidad que es internacional porque no solo está integrada por Estados, sino también por otros miembros que mantienen entre sí un mayor grado de sociabilidad en las relaciones internacionales en la medida en que han surgido intereses y valores generales compartidos y en la que se ha forjado un sentimiento de pertenencia a la misma. Además, es una comunidad política porque sus miembros pueden participar, con diferente grado de auto-

* Queremos agradecer sinceramente las observaciones y sugerencias formuladas a una versión previa de este trabajo por los dos revisores anónimos que han intervenido en el proceso de aceptación del mismo en esta Revista. Todas ellas han servido para mejorar el resultado final del mismo. Ángel J. Rodrigo (angel.rodrigo@upf.edu) es Profesor Titular de Derecho internacional público de la Universitat Pompeu Fabra, y Marta Abegón (marta.abegon@upf.edu) es Profesora visitante doctora de Derecho internacional público de la Universitat Pompeu Fabra. 
nomía, en el proceso de identificación, protección y regulación de tales intereses en el espacio público internacional por medio de políticas públicas globales y de normas e instituciones jurídicas internacionales. Dicha comunidad es también una comunidad jurídica cada vez más compleja en la que, junto a las tradicionales estructuras bilateral e institucional, existe una creciente estructura comunitaria integrada por normas e instituciones destinadas a la protección y regulación de los intereses y valores generales de la comunidad internacional en su conjunto. La suma de las aportaciones jurídicas que constituyen esta estructura comunitaria ha transformado cualitativamente el Derecho internacional convirtiéndolo en un auténtico Derecho internacional público ${ }^{1}$.

En dicha comunidad, junto a los intereses particulares de sus miembros y a los intereses comunes de algunos de ellos, se puede identificar un creciente número de intereses generales cuya gobernanza política y protección jurídica plantea en la actualidad importantes retos ${ }^{2}$. Los intereses generales de la comunidad internacional, el interés público global, son cualitativamente diferentes porque no son el resultado de la agregación de intereses particulares sino que son «una abstracción construida racionalmente» en el espacio público internacional. A su vez, algunos de estos intereses están protegidos y regulados por normas jurídicas internacionales, a las que se puede denominar normas de interés público internacional. Este tipo de normas se caracterizan, principalmente, por su objeto y fin, la protección de alguno de los intereses generales que la comunidad internacional haya reconocido como tales y considerado necesario otorgarles regulación jurídica; y porque de ellas se derivan obligaciones de estructura integral. Tales normas pueden ser creadas por medio de cualquiera de los procedimientos que existen en el ordenamiento jurídico internacional. No obstante, dadas las características específicas que tienen cada uno de dichos procedimientos, algunos de ellos parecen más adecuados para la protección del interés público global.

Los tratados de protección de intereses generales de la comunidad internacional $^{3}$, por sus particulares rasgos, se revelan como unos de los instru-

\footnotetext{
1 Rodrigo, A. J., «Entre Westfalia y Worldfalia: La comunidad internacional como comunidad social, política y jurídica», en GARcía, C. (dir.), La tensión cosmopolita. Avances y límites en la institucionalización del cosmopolitismo, Madrid, Tecnos, 2016, pp. 23-63; CaSANOvas, O., «La dimensión pública del Derecho internacional actual», en Bouza, N., García, C. y Rodrigo, Á. J. (dirs.) y PAREJA, P. (coord.), $L a$ gobernanza del interés público global. XXV Jornadas de la Asociación Española de Profesores de Derecho Internacional y Relaciones Internacionales, Barcelona, Tecnos, 2015, pp. 57-75.

2 GAJA, G., "The Protection of General Interests in the International Community», R. des $C$., vol. 364, 2013, pp. 1-185; también BouZA, N., GARcía, C. y Rodrigo, Á. J. (dirs.) y PAREJA, P. (coord.), op. cit., nota 2 .

3 La doctrina ha utilizado denominaciones diversas («tratados colectivos», «tratados multilaterales generales»...) para dar cuenta de aquellos tratados con vocación universal donde participan un número indeterminado de partes en contraposición con otros tratados multilaterales de naturaleza más restringida. No obstante, para poner de relieve la voluntad de este tipo de tratados de establecer normas jurídicas de alcance general y obligatorias para sus destinatarios, es preferible el término «tratado normativo general» o mejor el de «tratado multilateral normativo». La adición «de protección de intereses generales de la comunidad internacional» pretende destacar la función de las normas que incorpora,
} 
mentos más adecuados para llevar a cabo tal función. Por ello, el presente trabajo tiene por objeto contribuir a perfilar y profundizar en su noción y características. En este sentido, en el primer apartado se examina la noción de tratados de protección de intereses generales de la comunidad internacional (2), a los que se define como tratados multilaterales que tienen por objeto la regulación y protección de intereses generales de la comunidad internacional mediante la creación de algunas normas de interés público de las que se derivan obligaciones de estructura integral que tienen una vocación universal. En el siguiente apartado (3) se identifican y analizan sus características principales: la protección y regulación de intereses generales de la comunidad internacional como su objeto y fin; la estructura integral de algunas de sus obligaciones; y la vocación de universalidad, en especial, de las normas sustantivas de interés público en ellos contenidas. A continuación, se examinan algunas de las consecuencias que los tratados objeto de estudio tienen en la evolución y flexibilización del Derecho de los tratados como son, entre otras, la democratización en el proceso de elaboración y adopción de tratados; la erosión del papel del consentimiento; y su capacidad de adaptación al cambio a través de la creación de regímenes internacionales generales (4). Finalmente, el trabajo concluye con unas consideraciones finales (5).

\section{LA NOCIÓN DE TRATADOS DE PROTECCIÓN DE INTERESES GENERALES DE LA COMUNIDAD INTERNACIONAL}

Los tratados de protección de intereses generales son un tipo de instrumento normativo utilizado por los miembros de la comunidad internacional para la protección y regulación del interés público global. En la doctrina iusinternacionalista se han elaborado diferentes propuestas de definición que han contribuido a refinar progresivamente su noción. Así, en 1962, la Comisión de Derecho Internacional (CDI) definió los tratados multilaterales generales como aquellos tratados relativos «a normas generales de Derecho internacional o referentes a asuntos de interés general de todos los Estados» ${ }^{4}$.

Por su parte, Alejandro J. Rodríguez Carrión afirmó que dichos tratados:

«Serían uno de los medios más corrientemente utilizados para establecer reglas de conducta para el conjunto de Estados, no solamente en sus relaciones recíprocas, sino también no recíprocas respecto de los individuos, de los espacios comunes o de la humanidad en su conjunto. Mediante ellos, los Estados contribuyen al desarrollo del Derecho internacional, haciéndose intérpretes de las exigencias generales de la comunidad internacional» ${ }^{5}$.

así como su objeto de protección. Por razones de fluidez, en este estudio se utilizará indistintamente el término completo, el de «tratados multilaterales normativos de protección de intereses generales» o, preferentemente, el más sintético de «tratados de protección de intereses generales».

${ }_{4}$ Anuario de la Comisión de Derecho Internacional, vol. II, 1962 (A/CN.4/SER.A/1962/Add. 1), p. 186.

5 Rodríguez Carrión, A. J., «Un supuesto de superación del contractualismo en Derecho internacional: los tratados colectivos", en VVAA, Política y Sociedad. Estudios en Homenaje a Francisco Murillo Ferrol, Madrid, CIS/CEC, 1987, pp. 325-345, p. 330. 
De un modo similar, Lea Brilmayer utiliza el término "promesas» (pledges) para hacer referencia a los tratados internacionales sobre derechos humanos y sobre protección del medio ambiente en los que no hay un intercambio recíproco de contraprestaciones sino "promesas independientes y paralelas para respetar normas morales preexistentes ${ }^{6}$.

Una propuesta más reciente, de carácter descriptivo, los considera como:

«Tratados multilaterales que tienen una vocación universal, resultado de su adopción en el marco de foros más o menos institucionalizados abiertos a la participación de todos los Estados mediante un método colectivo de negociación, en los que la condición de parte está abierta a todos, o a prácticamente todos los Estados, y cuyo objetivo es regular y proteger los intereses generales de la comunidad internacional en su conjunto mediante la creación de obligaciones de naturaleza integral» ${ }^{7}$.

A partir de este primer ensayo, se propone una definición más sintética de los tratados de protección de intereses generales como:

«Los tratados multilaterales que tienen por objeto la regulación y protección de intereses generales de la comunidad internacional mediante la creación de algunas normas de interés público de las que se derivan obligaciones de estructura integral que tienen una vocación universal».

Esta concepción pone de manifiesto que estos tratados son una de las fuentes de creación de normas de interés público internacional y que se caracterizan, desde el punto de vista sustantivo, porque su objeto y fin primordial es la regulación de intereses generales de la comunidad internacional; desde el punto de vista de las obligaciones incluidas, porque algunas de ellas tienen una estructura integral; y, por sus características formales, porque tienen una vocación de universalidad, en especial, las normas de interés público en ellas contenidas. Este tipo de tratados, como se verá más adelante, suponen un reto para las reglas tradicionales del Derecho de los tratados porque deben dar respuesta a nuevas necesidades y, a la vez, contribuyen a su evolución. Además, las exigencias sustantivas y funcionales inherentes a la protección de los intereses generales demandan la incorporación de mecanismos para la adaptación al cambio y para su gestión activa que suelen dar origen a regímenes internacionales generales, que son auténticos laboratorios jurídicos en los que se ensayan nuevas respuestas sustantivas, institucionales y procedimentales.

\footnotetext{
${ }^{6}$ Brilmayer, L., "From "Contract" to "Pledge": The Structure of International Human Rights Agreements", British Yearbook of International Law, vol. 77, 2006, pp. 163-202, en particular, pp. 168172. No obstante, tanto el término pledges como su definición suscitan, en nuestra opinión, dificultades. El término "promesas» (pledges) puede interpretarse como que no se trata de obligaciones jurídicas sino de compromisos políticos. Y la definición como instrumentos para positivizar «normas morales preexistentes» presupone que todos los intereses generales de la comunidad internacional son de carácter moral y objetivo derivados de una filosofía de valores que generan obligaciones por sí mismos. Como se verá, los intereses generales son «construcciones sociales racionales» que pueden ser objeto de decisiones normativas por parte de los miembros de la comunidad internacional.

7 ABEgón, M., Los efectos de los conflictos armados en los tratados multilaterales normativos de protección del medio ambiente, tesis doctoral inédita, leída el 12 de diciembre de 2012 en la Universitat Pompeu Fabra, p. 252.
} 


\section{LAS CARACTERÍSTICAS DE LOS TRATADOS DE PROTECCIÓN DE INTERESES GENERALES}

Los principales rasgos que caracterizan los tratados de protección de intereses generales son tres: su objeto y fin, la regulación y protección de los intereses generales de la comunidad internacional; la estructura integral de las obligaciones derivadas de las normas de interés público en ellos contenidas, vinculada a su consideración de tratados normativos; $y$ su vocación de universalidad, derivada de su condición de tratados multilaterales y, en especial, de las normas de interés público. A continuación se examinan en detalle dichas características.

\subsection{El objeto y fin: la protección de intereses generales de la comunidad internacional}

La conclusión de tratados multilaterales normativos se explica por su especial función en el marco de la estructura comunitaria del Derecho internacional a cuya construcción y conformación contribuyen de forma decisiva. Por ello, el primer rasgo definitorio de los mismos, y el que los caracteriza desde un punto de vista sustantivo, es su objeto y fin: la protección y regulación de intereses generales de la comunidad internacional.

En la comunidad internacional actual se encuentran presentes diferentes tipos de intereses: los intereses particulares de sus miembros en alcanzar sus objetivos; los intereses comunes de algunos de ellos, muy especialmente de los Estados; y los intereses colectivos, de un grupo de Estados o bien generales de la comunidad internacional. Estos últimos no tienen un carácter objetivo, no están predeterminados ni poseen un contenido fijo e inamovible, sino que son una construcción social que es el resultado de la interacción entre todos los miembros de la comunidad internacional (y no solo los Estados), entre normas jurídicas e instituciones ya existentes, entre ideas socialmente compartidas y entre las identidades de dichos miembros.

Los intereses generales de la comunidad internacional se caracterizan por varios rasgos: porque tienen una dimensión comunitaria ya que son cualitativamente diferentes a la mera agregación de intereses individuales; porque se trata de «construcciones sociales racionales» fruto de la deliberación racional en el espacio público internacional para dar respuesta a problemas y necesidades concretas; porque tienen una dimensión intergeneracional; porque no son una fuente autónoma de obligaciones internacionales sino que, por el contrario, están sujetos a decisiones normativas de la comunidad internacional; porque su protección afecta a todos y no se encuentra subordinada a la satisfacción de los intereses estatales individuales ni a la reciprocidad mutua entre los Estados; y porque se encuentran regulados a través de una gran diversidad de técnicas jurídicas que han dado origen, a su vez, a distintos estatutos de protección (Patrimonio común de la humanidad, preocupación común de la humanidad, etc.). 
Dado que el interés público global es una construcción social, es muy importante prestar atención a la identificación y determinación de dichos intereses generales. La identificación no está atribuida a ningún Estado ni grupo en particular, sino que se trata de una tarea en la que pueden participar diferentes tipos de miembros de la comunidad internacional como los Estados y las organizaciones internacionales o los integrantes de la sociedad civil glo$\mathrm{bal}^{8}$. Efectivamente, al tratarse de la identificación de intereses, problemas o valores compartidos, desempeñan un papel esencial en este proceso las organizaciones internacionales y, en especial, Naciones Unidas y sus organismos especializados. Estas, tradicionalmente, han llevado a cabo una labor de denuncia, debate, determinación e investigación de problemas y retos a los que la comunidad internacional debe hacer frente. La complejidad y heterogeneidad de dicha tarea ha requerido, asimismo, prestar atención a problemas y necesidades de origen no estrictamente estatal y en ello han tenido también un rol destacado algunos actores de la sociedad civil global, como son las organizaciones no gubernamentales. En este sentido, el Comité Internacional de la Cruz Roja en el campo de los Derechos Humanos, o "Greenpeace» en materia medioambiental, entre otras, han contribuido indudablemente a centrar la atención pública en determinados ámbitos de interés común.

El proceso de identificación de estos intereses generales debe tener lugar por medio de un diálogo inclusivo orientado a alcanzar un consenso intercultural e intersocial en torno a cuáles son los problemas y necesidades colectivos. Con el fin de incrementar la legitimidad de dicho proceso y eludir el riesgo de instrumentalización ${ }^{9}$, dicho diálogo se produce en el espacio público internacional en diferentes planos (social, político, mediático, etc.) y ámbitos (público, privado), lo que permite a alcanzar con frecuencia acuerdos cada vez más amplios acerca de la urgencia de proteger determinados bienes, espacios, recursos, necesidades, problemas o valores que pueden, o no, estar sometidos a la jurisdicción estatal. Como resultado de dicho diálogo, y aunque no exista una lista fija e inmutable en tanto que el interés general varía y evoluciona a lo largo del tiempo de acuerdo con la propia agenda internacional y los factores políticos, económicos o sociales que influyen en ella, en la actualidad se pueden considerar intereses generales la protección de la dignidad humana y de los derechos humanos, el mantenimiento de la paz y la seguridad internacionales, la garantía del progreso y el desarrollo social y humano, la protección del medio ambiente o la salvaguarda de determinados espacios (la Zona Internacional de los Fondos Marinos y Oceánicos, la Antártida, la Luna y otros cuerpos celestes) y recursos necesarios para la humanidad.

\footnotetext{
8 Pardo, A. y Christol, C. Q., «The Common Interest: Tension Between the Whole and the Parts», en Macdonald, R. S. J. y Johnston, D. M. (eds.), The Structure and Process of International Law: Essays in Legal Philosophy, Doctrine and Theory, La Haya, Boston, Martinus Nijhoff Publishers, 1983, pp. 643660, p. 644.

9 Koskenniemi, M., The Gentle Civilizer of Nations, Cambridge, Cambridge University Press, 2002, pp. 98-166; y también en «International Law in Europe: Between Tradition and Renewal», EJIL, vol. 16, 2005, núm. 1, pp. 113-124; RodRigo, Á. J., «El Derecho internacional hegemónico y sus límites», Anuario Español de Derecho Internacional, vol. XXIII, 2007, pp. 147-207.
} 


\subsection{La estructura integral de algunas de sus obligaciones}

Un segundo rasgo definitorio de los tratados objeto de estudio, derivado de su condición de tratados normativos, es que contienen algunas obligaciones de estructura integral ${ }^{10}$. La noción de obligación integral debe su origen al Relator especial de la Convención de Viena sobre el Derecho de los Tratados (CVDT), Gerald Fitzmaurice, quien, durante los trabajos de elaboración de esta, distinguió entre diferentes tipos de tratados en función de la naturaleza o estructura de sus obligaciones. Así, por una parte señalaría la existencia de tratados ordinarios (bilaterales o multilaterales), es decir, tratados de naturaleza bilateral que prevén un intercambio de prestaciones mutuas o de actos bajo una base de reciprocidad, y cuyo incumplimiento por una de las partes facultaría a la parte afectada a incumplir en la misma medida; y, por otra, otro tipo de tratados multilaterales cuyo funcionamiento diferiría radicalmente del anterior al no estar fundamentado en ninguna base de reciprocidad sino en obligaciones de una clase «más absoluta» ${ }^{11}$. Dentro de esta segunda categoría, cabría distinguir, en primer lugar, los tratados multilaterales de naturaleza interdependiente, cuyas obligaciones "o se cumplen íntegramente o no se cumplen en absoluto» ${ }^{12}$, en los cuales el cumplimiento de las obligaciones por una de las partes depende del correspondiente cumplimiento por el resto de partes, de forma que el incumplimiento de una parte puede dar lugar al incumplimiento por parte del resto; y los tratados de naturaleza integral, en los cuales sus obligaciones son autónomas e independientes para cada una de las partes y no se encuentran subordinadas en ninguna medida a su cumplimiento por parte del resto ${ }^{13}$. Como señaló el propio Relator especial:

«Debido a la naturaleza misma del tratado, ni jurídicamente ni desde el punto de vista práctico la obligación de una de las partes depende del cumplimiento correspondiente por las otras. La obligación tiene carácter absoluto más bien que recíproco; se trata, por decirlo así, de una obligación para con todos más que para con algunas partes determinadas» ${ }^{14}$.

Así, utilizando la clasificación de las obligaciones internacionales en función de su estructura, las obligaciones derivadas de las normas de interés público que puedan existir en los tratados de protección de intereses generales tienen una estructura integral. En concreto, serían obligaciones erga omnes partes un tipo de tales obligaciones «que derivan de un tratado multilateral a

10 Véase el Segundo informe sobre las reservas a los tratados, preparado por el Sr. Alain Pellet, Relator especial, de 13 de junio de 1996 (A/CN.4/477/Add. 1), pp. 13-15, párrs. 83-88. Aunque no todas las disposiciones de un tratado normativo contienen obligaciones integrales (estos pueden contener disposiciones de naturaleza contractual y de hecho es muy frecuente que las contengan), es la incorporación de algunas normas de interés público de las que se derivan obligaciones integrales entre sus disposiciones lo que constituye una característica definitoria de este tipo de tratados.

${ }_{11}$ Anuario de la Comisión de Derecho Internacional, vol. II, 1958 (A/CN.4/SER.A/1958/ Add.l), p. 48, párr. 91.

12 Anuario de la Comisión de Derecho Internacional, vol. II, 1957 (A/CN.4/SER.A/1957/Add.l), p. 58, párr. 120 .

${ }_{13}$ Anuario de la Comisión de Derecho Internacional, vol. II, 1958, op. cit., nota 12, p. 48, párr. 91.

${ }^{14}$ Anuario de la Comisión de Derecho Internacional, vol. II, 1957, op. cit., nota 13, p. 58, párr. 126. 
las que un Estado está sometido en todas las circunstancias hacia los demás Estados parte del tratado, en razón de valores que les son comunes y de su interés en que estas obligaciones sean respetadas, de tal manera que su violación autoriza a los demás Estados a reaccionar» ${ }^{15}$.

Las obligaciones erga omnes partes derivadas de las normas de interés público que contienen este tipo de tratados obligan a todos los Estados parte del tratado, operan de manera integral y no se pueden descomponer en haces de relaciones bilaterales entre los diferentes Estados parte. Se trata de obligaciones «absolutas» debido a su falta de reciprocidad. En particular, ello se traduce en que su cumplimiento es autónomo y no depende del correspondiente cumplimiento por el resto de partes en el tratado. La naturaleza de los intereses protegidos por este tipo de obligaciones promueve un mismo interés de todos los Estados en que estas sean respetadas y cumplidas y, en consecuencia, su incumplimiento "afecta a todos los destinatarios, sean un grupo de Estados o la comunidad internacional en su conjunto» ${ }^{16}$.

Dichas obligaciones tienen también un carácter solidario en tanto que su incumplimiento afecta a todos los Estados destinatarios, teniendo todos ellos un mismo interés legal en su protección ${ }^{17}$. Cuando una obligación de este tipo es incumplida, se genera una respuesta tanto en el marco del propio tratado como, en general, en el ámbito de la exigencia de responsabilidad internacional. En este sentido, el Proyecto de artículos sobre la responsabilidad del Estado por hechos internacionalmente ilícitos prevé que, ante un incumplimiento por una parte de una obligación integral, todo Estado que no sea el Estado lesionado podrá invocar la responsabilidad de otro Estado si: «La obligación violada existe con relación a un grupo de Estados del que el Estado invocante forma parte y ha sido establecida para la protección de un interés colectivo del grupo» (obligaciones erga omnes partes); o si «la obligación violada existe con relación a la comunidad internacional en su conjunto» (obligación erga omnes) (art. 48) ${ }^{18}$. La invocación de responsabilidad comportará la posibili-

15 Résolution «Les obligations et les droits erga omnes en Droit International», Institut de Droit International, Cracovia, 27 de agosto de 2005, art. 1.b). La traducción es nuestra.

16 Casanovas, O. y Rodrigo, Á. J., Compendio de Derecho internacional público, 5. a ed., Madrid, Tecnos, 2016, p. 48.

17 Rodrigo, Á. J., "Nuevas técnicas jurídicas para la aplicación de los tratados internacionales del medio ambiente», Cursos de Derecho internacional y Relaciones internacionales de Vitoria-Gasteiz, 2001, pp. 157-243, p. 184.

${ }_{18}$ Informe de la Comisión de Derecho Internacional sobre la labor realizada en su 53 periodo de sesiones, de 23 de abril a 1 de junio y de 2 de julio a 10 de agosto de 2001, Asamblea General. Documentos oficiales. 56 periodo de sesiones, Suplemento N. 10 (A/56/10), pp. 20-153, en pp. 134 y 147, respectivamente. Sobre la posibilidad de adoptar medidas lícitas y sobre el «incierto» estado actual del Derecho internacional acerca de las contramedidas adoptadas en interés general o colectivo, véanse los comentarios al proyecto de artículos, así como, por ejemplo: ALlAND, D., «Counter measures of General Interest», EJIL, vol. 13, 2002, núm. 5, pp. 1221-1239; y GuTIÉRrEz EsPADA, C., «Las contramedidas de Estados "terceros" por violación de ciertas obligaciones internacionales", AADI, vol. XI, 2001-2002, pp. 15-49. Es preciso apuntar que se prevén disposiciones equivalentes para las Organizaciones internacionales en los arts. 43 y 57 del Proyecto de artículos de la CDI sobre responsabilidad internacional de las Organizaciones internacionales, Informe de la Comisión de Derecho Internacional sobre la labor realizada en su 63 periodo de sesiones, de 26 de abril a 3 de junio y de 4 de julio a 12 de agosto de 2011, 
dad de exigir al Estado que ha violado la obligación el cese de tal violación y la reparación de los daños derivados del ilícito, en interés del Estado lesionado o de los beneficiarios de la obligación violada. Asimismo, Estados distintos del lesionado podrán adoptar medidas lícitas contra el Estado responsable para asegurar la cesación de la violación y su reparación (art. 54).

\subsection{La vocación de universalidad}

La tercera característica de los tratados de protección de intereses generales y, en especial, de las normas de interés público en ellos contenidas es su vocación de universalidad. Este rasgo denota, por un lado, la aspiración a la participación universal en los primeros y, por otro lado, la pretensión de las normas de interés público contenidas en tales tratados de tener alcance universal y ser aplicables a todos los Estados. La vocación de universalidad no significa necesariamente que tales tratados y normas sean ya obligatorios y aplicables para todos, ya que, como es bien sabido, los tratados obligan a las partes (art. 26 CVDT) y no pueden crear derechos y obligaciones para un tercer Estado sin su consentimiento (art. 34 CVDT). Es una aspiración que está justificada por su objeto y fin, la protección y regulación jurídica de tales intereses generales de la comunidad internacional. Dado que, en general, las diferentes manifestaciones del interés público global tienen un alcance universal, parece razonable y aun deseable que su regulación jurídica fuera llevada a cabo por normas que también fueran universales. En otras palabras, en la comunidad internacional existe una demanda creciente de normas universales para la protección del interés público global.

La vocación de universalidad de estos tratados y normas es una tendencia que está estimulada por medio de diferentes estrategias: facilitando la participación y su apertura; por medio de las interacciones con las normas consuetudinarias; e incentivando la ampliación subjetiva y territorial de sus efectos.

\subsubsection{La flexibilización en la participación y la apertura de los tratados}

La vocación de universalidad de este tipo de tratados es una consecuencia de la posibilidad de que participen en su elaboración el mayor número posible de Estados en cuanto partes originarias y de su grado de apertura a la participación de nuevas partes durante la vigencia del mismo. Los tratados objeto de estudio son, por una parte, multilaterales; y, por otra, son abiertos en la medida en que permiten la participación de nuevos Estados distintos a los originarios.

Asamblea General. Documentos oficiales. 66 periodo de sesiones, Suplemento N. 10 (A/66/10), pp. 53184, en pp. 145 y 167, respectivamente. 
En relación al grado de apertura, durante el proceso de adopción de las Convenciones sobre relaciones diplomáticas de 1961 y sobre relaciones consulares de 1963 se planteó la cuestión de si los tratados multilaterales de carácter general que contenían normas de interés para la comunidad internacional debían ser tratados abiertos (tesis defendida por los Estados socialistas) o, como los ha denominado Cesáreo Gutiérrez Espada, tratados semicerrados (tesis defendida por los Estados occidentales), «cuya adhesión se subordina al cumplimiento por el candidato de determinados requisitos» ${ }^{19}$. El acuerdo entre ambas tesis consistió en la llamada fórmula de Viena, que abre el tratado a la firma o a la adhesión de los miembros de las Naciones Unidas o de otros Estados que se enuncian en los artículos correspondientes de tales convenciones y a cualquier otro Estado invitado por la Asamblea General $^{20}$.

La misma cuestión se planteó durante el proceso de codificación del derecho de los tratados en la CDI. En ella, si bien existía unanimidad acerca del «especial carácter» de los tratados multilaterales generales y lo deseable de que estos «fueran, en principio, abiertos a una participación lo más extensa posible por parte de los Estados» ${ }^{21}$, la concreción de dicha idea dividió a sus miembros: para algunos de ellos, en la medida en que dichos tratados tienen como objeto alcanzar un bien común para toda la comunidad internacional, en ningún caso un Estado podría ser excluido ${ }^{22}$; para otros, debía prevalecer el principio general de la autonomía de la voluntad estatal. La CVDT de 1969 recoge prácticamente la fórmula de Viena (arts. 81 y 83) y en la Conferencia se adoptó la «Declaración relativa a la participación universal en la Convención de Viena sobre el derecho de los tratados», en la que se pueden resaltar dos elementos que pueden explicar el sentido de la evolución posterior de la práctica convencional en esta materia: por un lado, se reconoce explícitamente que «los tratados multilaterales [...] cuyo objeto y fin son de interés para la comunidad internacional en su conjunto deberían estar abiertos a la participación universal»; y, por otro lado, se invita a la Asamblea General a que «considere la cuestión del envío de invitaciones a fin de asegurar la máxima participación posible» ${ }^{23}$. Parece, por tanto, que las reticencias apuntadas a la apertura de los tratados de protección de intereses generales respondían más a una situación política coyuntural (la guerra fría) que a razones de fondo. Por ello, cabe concluir que existe una opinión generalizada acerca de que los tratados de protección de intereses generales deberían estar abiertos a la par-

19 Véase la polémica sobre este tema en GutiérRez EsPada, C., Derecho internacional público, Madrid, Trotta, 1995, pp. 313-315.

${ }_{20}$ Sobre la fórmula de Viena puede verse ibid., nota 20, pp. 314-315. La Convención de Viena sobre relaciones diplomáticas de 1961, BOE núm. 21, de 24 de enero de 1968, incorpora dicha fórmula en sus arts. 48 y 51. Y la Convención de Viena sobre relaciones consulares de 1963, BOE núm. 56, de 6 de marzo de 1970, incluye la fórmula de Viena en sus arts. 74 y 76.

${ }^{21}$ Anuario de la Comisión de Derecho Internacional, vol. II, 1962, op. cit., nota 5, p. 194, párr. 2.

22 Ibid., p. 168.

${ }^{23}$ Véase el texto de la CVDT de 1969 y la Declaración citada en BOE núm. 142, de 13 de junio de 1980. 
ticipación más amplia posible por parte de los Estados ${ }^{24}$. Además, la práctica convencional posterior confirma tanto la apertura de los tratados de codificación ${ }^{25}$ como de los tratados de protección de intereses generales.

\subsubsection{La contribución a la creación de normas jurídicas de alcance universal}

La vocación de universalidad de estos tratados y de las normas de interés público en ellos contenidas se manifiesta también en sus relaciones con otras normas universales de Derecho internacional general y, en particular, con las normas consuetudinarias. La aspiración de universalidad de estos tratados y normas favorecen la creación de nuevas normas consuetudinarias de alcance general ya sea porque produzcan un efecto cristalizador sobre el proceso consuetudinario que ya estuviera en marcha, o bien porque promueva un efecto generador de nuevas normas consuetudinarias como consecuencia de su incorporación en el tratado ${ }^{26}$. La contribución de los tratados multilaterales normativos a la cristalización de normas consuetudinarias supone que, ante una práctica ya existente, estos pueden servir como prueba de la opinio iuris necesaria para que dicha práctica pueda ser considerada una costumbre internacional. La adopción de un tratado multilateral recogiendo el mismo contenido de la conducta objeto de la práctica previa constituiría un «acto suficientemente relevante» ${ }^{27}$ para lograr la cristalización de dicha práctica como costumbre ${ }^{28}$.

24 Alejandro J. Rodríguez Carrión señala que «por definición, un tratado colectivo tiene que mostrar una absoluta generosidad en cuanto a la posibilidad de adhesiones de nuevos Estados [...] la naturaleza legislativa de un tratado colectivo impone la posibilidad de su apertura a todos los Estados, de su vocación universal», RODRíGUEZ CARRIón, A. J., op. cit., nota 6, pp. 336-337.

25 GutiérReZ EsPaDA, C., op. cit., nota 20, p. 315.

${ }^{26} \mathrm{La}$ interacción entre costumbre y tratado, plasmada en un efecto declarativo, cristalizador y constitutivo o generador de la primera a través del segundo, fue desarrollada por JIMÉNEZ DE ARÉCHAGA, A., en «Internacional Law in the Past Third of a Century», $R$. des $C$., vol. 159, 1978, pp. 1-343, en pp. 1422. Sobre dicha interacción, véase, por ejemplo: BADIA MARTí, A. (dir.), «La aportación de las Naciones Unidas a la codificación y desarrollo progresivo del Derecho internacional», Colección Escuela Diplomática, núm. 2, Jornadas sobre el 50 Aniversario de las Naciones Unidas, Madrid, 1995, pp. 121-174; Blanc Altemir, A., "Consideraciones en torno al proceso de formación de las normas jurídicas internacionales", Boletín de Información del Ministerio de Justicia, núm. 1650, de 15 de octubre de 1992, pp. 74-106; Pastor Ridruejo, J. A., «Las Naciones Unidas y la codificación del Derecho Internacional: aspectos jurídicos y políticos», en Fernández de Casadevante, C. y Quel, F. J. (coords.), Las Naciones Unidas y el Derecho Internacional, Barcelona, Ariel, 1997, pp. 173-187; Pons RÀFols, X., «España y la Comisión de Derecho Internacional: balance a los 50 años de su creación», Agenda ONU, 1998, núm. 1, pp. 149-164; López MARTín, A. G., «La codificación del Derecho internacional en el umbral del siglo XXI: luces y sombras en la labor de la CDI», Anuario hispano-luso-americano de derecho internacional, vol. X, 2001, pp. 367-390; y Quel López, F. J. y Álvarez Rubio, J. J., La codificación del Derecho Internacional, Bilbao, 2004.

27 Díez de Velasco, M. y Escobar, C. (coords.), Instituciones de Derecho internacional público, 18. ${ }^{\mathrm{a}}$ ed., Madrid, Tecnos, 2013, p. 147.

${ }_{28}$ Conviene precisar que si bien los tratados multilaterales normativos son mucho más susceptibles de servir de prueba de dicha opinio iuris que los tratados bilaterales o los tratados multilaterales de naturaleza restrictiva, será necesario en cada caso examinar tanto las disposiciones del texto final resultante de la negociación, esté o no en vigor, como las manifestaciones efectuadas por los Estados 
Asimismo, las obligaciones integrales insertas en tratados de protección de intereses generales sirven también para generar nuevas costumbres internacionales. Ello supone que son las disposiciones con carácter fundamentalmente normativo del propio tratado ${ }^{29}$ las que dan lugar una práctica constante y uniforme, arropada por la convicción de que esta resulta jurídicamente obligatoria. En este segundo supuesto, lo verdaderamente representativo es la práctica posterior de los Estados no parte en el tratado: el seguimiento generalizado de la conducta prescrita por el tratado por parte de estos supondría una evidencia del surgimiento de una nueva norma consuetudinaria y, en última instancia, tendría como efecto que, salvo un eventual objetor persistente $^{30}$, todos los Estados de la comunidad internacional quedarían vinculados por esta nueva norma consuetudinaria de contenido idéntico al de la correspondiente disposición del tratado originario ${ }^{31}$.

\subsubsection{La ampliación subjetiva y territorial de sus efectos}

La universalidad de los tratados de protección de intereses generales puede incrementarse, finalmente, incentivando la ampliación subjetiva y territorial de sus efectos. La ampliación subjetiva se manifiesta en relación con los Estados que no son parte y también respecto a los actores no estatales. La

durante su negociación, ya que en algunos supuestos puede desprenderse de estas la voluntad de los Estados de que las normas contenidas en el tratado sean obligatorias únicamente en tanto que obligaciones convencionales, MARTín LÓPEZ, M. A., La formación de los Tratados Internacionales. Estudio de su condicionamiento por el consentimiento del Estado y el medio y los intereses colectivos, Córdoba, Servicio de Publicaciones de la Universidad de Córdoba, 2002, p. 151. En este mismo sentido, la admisión de determinadas reservas o la posibilidad de denunciar el tratado pueden ser indicativos de que no existe la convicción de que la conducta reflejada en la norma del tratado sea jurídicamente obligatoria.

29 Asunto de la Plataforma continental del Mar del Norte (República Federal de Alemania/Dinamarca; República Federal de Alemania/Países Bajos), Sentencia de 20 de febrero de 1969 (ICJ Reports, 1969), pp. 41-42, párr. 72 .

${ }^{30}$ Tal y como está siendo contemplado en los trabajos de la CDI sobre la identificación del Derecho internacional consuetudinario: «Cuando un Estado haya objetado a una norma de derecho internacional consuetudinario mientras esta se encontraba en proceso de formación, esa norma no será oponible a ese Estado siempre que mantenga su objeción». Igualmente, la objeción deberá ser «expresada claramente, ser comunicada a los demás Estados y ser mantenida de manera persistente», Texto de los proyectos de conclusión aprobados provisionalmente por el Comité de Redacción (A/CN.4/L.869), 15 de julio de 2015, p. 4, art. 15. Dicha posibilidad ha sido también cuestionada por la doctrina. Jonathan I. Charney señala, por ejemplo, que: "The persistent objector rule, if it really exists, focuses more on the process of law development than on the status of a State under stable international law», CHARNEY, J. I., "The persistent objector rule and the development of customary international law», BYIL, vol. 56, 1985, pp. 1-24, p. 22. En este sentido, el Estado que se hubiera opuesto desde sus inicios a una determinada norma consuetudinaria, no por ello dejaría de estar obligado por la misma; por el contrario, su actitud lo que estaría cuestionando es la misma existencia de la norma, posicionamiento que debería ser tomado en consideración en el momento de determinar si la costumbre internacional ha llegado a cristalizar o no.

31 Se trata del supuesto regulado en el art. 38 CVDT. La importancia en este ámbito de los tratados objeto de estudio es tal, que la CIJ ha llegado a contemplar la posibilidad de dispensar el requisito de probar una práctica constante y uniforme posterior, a condición de que exista una muy amplia participación en el tratado y esta resulte suficientemente representativa, en la medida que incluya a los Estados especialmente interesados, Asunto de la Plataforma continental del Mar del Norte, op. cit., nota 30 , p. 43 , párr. 73 . 
existencia de un tratado de este tipo en un determinado ámbito puede producir efectos para terceros Estados en la medida en que el interés protegido, la creación de obligaciones de estructura integral y su vocación de universalidad no puede ser indiferente, ni siquiera neutral, para ningún miembro de la comunidad internacional ${ }^{32}$. Estos efectos, sin llegar en absoluto a suponer la creación de derechos y de obligaciones para terceros Estados sin su consentimiento (prohibida por el art. 34 CVDT), se evidencia, en primer lugar, en la incorporación de disposiciones que regulan las relaciones de los Estados parte en el tratado con respecto a terceros Estados: por ejemplo, instaurando la obligación de aquellos de promover la ratificación y el cumplimiento del tratado por parte de estos, estableciendo incentivos positivos o negativos para lograr su participación en el tratado, o bien otorgando a los terceros Estados el estatuto de observador en la Conferencia de las partes ${ }^{33}$.

En segundo lugar, facilita la ampliación subjetiva de sus efectos la aplicación del principio de integración sistémica para la interpretación de obligaciones contenidas en tratados de protección de intereses generales. El principio de integración sistémica establece que los tratados habrán de interpretarse teniendo en cuenta «toda forma pertinente de Derecho internacional aplicable en las relaciones entre las partes» [art. 31.3.c)]. En este sentido, la existencia de un tratado de este tipo en un determinado ámbito material puede condicionar significativamente la interpretación de otros tratados y acuerdos existentes sobre la misma materia: en la medida en que aquel «expresa las in-

32 En este sentido, algunos autores han defendido una interpretación particular del principio pacta tertiis en aquellos ámbitos jurídicos que son del interés general de la comunidad internacional, Lachs, M., "Le développement et les fonctions des traités multilateraux», $R$. des C., vol. 92 (II), 1957, pp. 229-341, en pp. 315-319. A juicio de Paul Reuter, «cuando los consentimientos o las instituciones emanan de un conjunto suficientemente representativo de Estados principalmente interesados en una cuestión, estos consentimientos o estas instituciones pueden, a veces, generar efectos para los terceros Estados», Reuter, P., «Principes de Droit International Public», R. des C., vol. 103 (II), 1961, pp. 425655 , en pp. 448-449. La traducción es nuestra. Igualmente, se ha defendido la flexibilización de la necesidad de consentimiento a favor del principio de efectividad, CARriLlo Salcedo, J. A., Soberanía del Estado y Derecho internacional, Madrid, Tecnos, 1969, pp. 185-194. Sobre los tratados que establecen regímenes objetivos, reconocidos por buena parte de la doctrina como una excepción al principio pacta tertiis pero no mencionados ni regulados en la CVDT, véase, entre otros: CAHIER, Ph., "Le probléme des effets des traités a l'égard des États tiers», $R$. des $C$., vol. 143, 1974, pp. 589-736; FitzmaURICE, M., "Third Parties and the Law of Treaties», Max Planck Yearbook of United Nations Law, vol. 6, 2002, pp. 37-137; MARTín LóPEz, M. A., «Estudio sobre los regímenes objetivos en el Derecho de los tratados», REEI, 2010, núm. 20, pp. 1-16; y RozAKIS, Ch. L., "Treaties and third states: a study in the reinforcement of the consensual standards in international law», Zeitschrift fur auslandisches offentliches Recht und Volkerrecht, vol. 40, 1975, pp. 1-40.

33 Constituyen ejemplos de dichas previsiones, el art. 21 de la Convención sobre las Bombas de Racimo, hecha en Dublín el 30 de mayo de 2008, BOE núm. 68, de 19 de marzo de 2010; el art. 8.1.a) de la Convención sobre prohibiciones o restricciones del empleo de ciertas armas convencionales que puedan considerarse excesivamente nocivas o de efectos indiscriminados, hecha en Ginebra el 10 de octubre de 1980, BOE núm. 89, de 14 de abril de 1994; o los arts. 8.3, 8.4, 8.5 y 33.2 del Acuerdo sobre la aplicación de las disposiciones de la Convención de las Naciones Unidas sobre el Derecho del mar de 10 de diciembre de 1982 relativas a la conservación y ordenación de las poblaciones de peces transzonales y las poblaciones de peces altamente migratorios de 1995, BOE núm. 175, de 21 de julio de 2004. En este sentido, véase Peters, A., "Compensatory Constitutionalism: The Function and Potential of Fundamental International Norms and Structures», Leiden Journal of International Law, vol. 19, 2006, Issue 3, pp. 579-610, en pp. 587-588. 
tenciones o entendimientos comunes» de todos sus Estados parte en relación con el sentido que debe darse a un determinado término ${ }^{34}$, deberá ser tenido en cuenta para interpretar las obligaciones contenidas en otros tratados. Más allá del debate doctrinal y jurisprudencial sobre el número de partes a las que las normas integradas les sean aplicables (todas las del tratado o solo a las partes en una controversia) ${ }^{35}$, el principio de integración sistémica, en cuanto técnica de integración normativa, permite exportar e importar todo o parte del contenido de las normas jurídicas que puede contribuir a la ampliación subjetiva de los efectos de los tratados de protección de intereses generales ${ }^{36}$.

En tercer lugar, los Estados que no son parte en un tratado de protección de intereses generales también pueden verse afectados por la existencia de aquel cuando se produzca un conflicto normativo entre dicho tratado y otros tratados o acuerdos en los que ellos formen parte. Las reglas generales de solución de conflictos normativos no suelen funcionar adecuadamente cuando lo que existe es un conflicto entre normas cuyas partes no son las mismas y, sobre todo, entre distintos regímenes de tratados ${ }^{37}$, y la tendencia es la de intentar coordinar en la medida que sea posible la aplicación simultánea de estas $^{38}$. Por ello, los tratados de protección de intereses generales suelen con-

34 Pauwelyn, J., Conflict of Norms in Public International Law. How WTO Law Relates to Other Rules of International Law, Cambridge, Cambridge University Press, 2003, p. 261; también ANDRÉS SAÉnZ de SANTA María, P., «El principio de integración sistémica y la unidad del Derecho internacional», en Rodrigo, A. J. y García, C. (eds.), Unidad y pluralismo en el Derecho internacional público y en la comunidad internacional, Madrid, Tecnos, 2011, pp. 356-374.

35 Una versión estricta es defendida por Mclachlan, C., «The Principle of Systemic Integration and Article 31 (3) c of the Vienna Convention", ICLQ, vol. 54, 2005, pp. 279-320, en pp. 313-315. En cambio, FRENCH, D., "Treaty Interpretation and the Incorporation of Extraneous Legal Rules», ICLQ, vol. 55, 2006, pp. 281-314, en pp. 305-307 sostiene una concepción más flexible, limitando la aplicabilidad a las partes en la controversia.

36 Un buen ejemplo se ha producido en el ámbito de la protección internacional de las mujeres por razones vinculadas a su género o a su identidad sexual. Estos supuestos no tienen regulación específica en los tratados internacionales que definen el estatuto de refugiado o las formas de protección subsidiaria de este estatuto. Ahora bien, el reconocimiento de derechos específicos a las mujeres por medio de los tratados internacionales de alcance regional o universal ha permitido a órganos como el Comité contra la Tortura, el Comité de Derechos Humanos o el TEDH realizar una interpretación de los tratados en los que operan sensible al género que permite proteger las formas específicas de persecución de malos tratos por razones de género o de identidad sexual. Véase MoRGADES, S., "La protection internationale des femmes pour des raisons liées au genre en droit international. Interprétations récentes des instruments de droit international soutenant des formes de protection subsidiaire», RGDIP, t. CXVII, 2013, núm. 1, pp. 37-73.

37 Fragmentación del Derecho internacional: dificultades derivadas de la diversificación y expansión del Derecho internacional, Informe del Grupo de Estudio de la Comisión de Derecho Internacional, elaborado por Koskenniemi, de 13 de abril de 2006 (A/CN.4/L.682), p. 157, párr. 272.

38 Un ejemplo de dicho criterio armonizador se encuentra en el preámbulo del Tratado Internacional sobre los Recursos fitogenéticos para la alimentación y la agricultura, hecho en Roma el 3 de noviembre de 2001, BOE núm. 109, de 5 de mayo de 2004, el cual reconoce que «el presente Tratado y otros acuerdos internacionales pertinentes deben respaldarse mutuamente con vistas a conseguir una agricultura y una seguridad alimentaria sostenibles»; también en el art. 20 de la Convención de la UNESCO sobre la protección y promoción de la diversidad de las expresiones culturales de 2005, BOE núm. 37, de 12 de febrero de 2007. Cfr. Peters, A., «The Refinement of International Law: From Fragmentation to Regime Interaction and Politization», MPIL Research Paper Series, 2016, núm. 19, pp. 1-25, en particular, pp. 13-18. 
tener cláusulas condicionales que intentan salvaguardar el núcleo esencial del tratado frente a anteriores o posteriores acuerdos que puedan celebrar las partes y que sean incompatibles con los principios generales del primero, con los derechos y obligaciones de las partes o, en general, que pongan en grave peligro su objeto de protección o la consecución de sus objetivos ${ }^{39}$.

La ampliación subjetiva de los efectos de los tratados objeto de estudio se produce también en relación con los actores no estatales. Como señala Rosario Huesa, en ciertos ámbitos del ordenamiento jurídico internacional, como en el Derecho internacional de los derechos humanos, ya se encuentra reconocida la ampliación del elenco de destinatarios de las normas a destinatarios que no son ni Estados ni Organizaciones internacionales ${ }^{40}$. El individuo ha devenido, así, titular de derechos internacionalmente reconocidos que los Estados tienen la obligación de proteger. Igualmente, los tratados de protección del medio ambiente establecen obligaciones dirigidas a las empresas. A ello hay que añadir, además, lo que la autora identifica como «elementos de inmediatez» entre las normas de interés público y los destinatarios no estatales, que se manifiestan, por ejemplo, en el ámbito de la responsabilidad penal internacional mediante la desvinculación entre la incriminación internacional y la tipificación penal interna, o en el ámbito de los derechos y libertades fundamentales, en la habilitación de mecanismos para la denuncia directa por parte de individuos víctimas de violaciones de derechos humanos ${ }^{41}$.

Por otro lado, la ampliación territorial de los efectos de los tratados de protección de intereses generales más allá del territorio de los Estados parte es una práctica cada vez más amplia, sólida y reconocida por los órganos y tribunales internacionales. Esta aplicación extraterritorial es una tendencia bien consolidada en el caso de los tratados de derechos humanos y empieza a serlo también en otros tipos de tratados de protección de intereses generales como los tratados medioambientales. La aplicación extraterritorial de los tratados de derechos humanos ha sido expresamente reconocida en el caso del Pacto internacional de derechos civiles y políticos. Así, la CIJ en su sentencia en el Asunto de las actividades armadas sobre el territorio del Congo (Congo c. Uganda), de 19 de diciembre de 2005, afirma que los instrumentos internacionales relativos a los derechos del hombre pueden ser de aplicación extraterritorial, «particularmente en los territorios ocupados» ${ }^{42}$.

\footnotetext{
39 Es el caso del art. 311.3 de la Convención de las Naciones Unidas sobre el Derecho del Mar, hecha en Montego Bay el 10 de diciembre de 1982, BOE núm. 39, de 14 de febrero de 1997; del art. 11 del Convenio de Basilea sobre el control de los movimientos transfronterizos de los desechos peligrosos y su eliminación, firmado el 22 de marzo de 1989, BOE núm. 227, de 22 de septiembre de 1994; o del art. 22 del Convenio sobre la diversidad biológica, hecho en Río de Janeiro el 5 de junio de 1992, BOE núm. 27, de 1 de febrero de 1994.

${ }^{40}$ Huesa, R., "La protección del interés público global: una nueva dimensión para las normas y obligaciones internacionales», en BouZa, N., GARcía, C. y Rodrigo, Á. J. (dirs.), op. cit., nota 2, pp. 253286 , p. 258.

${ }^{41}$ Ibid., pp. 259-260.

42 Sentencia de la CIJ en el Asunto de las actividades armadas sobre el territorio del Congo (Congo c. Uganda), de 19 de diciembre de 2005 (ICJ Reports 2005), párr. 216. En el mismo sentido véase la Opi-
} 
En la práctica y en la jurisprudencia se ha planteado también cada vez con más frecuencia si el Convenio Europeo de Derechos Humanos es aplicable solo en el territorio de los Estados parte o también lo es en el territorio de Estados no parte respecto de actos realizados por agentes de un Estado parte que tienen la condición de órganos del Estado. El TEDH, en el asunto AlSkeini, sistematizó su jurisprudencia anterior sobre la materia y admitió dos supuestos de aplicación extraterritorial del Convenio y, por tanto, de ampliación territorial de sus efectos. El primero es el relativo a los actos de los órganos de un Estado parte (agentes diplomáticos y consulares) realizados bajo su autoridad y control en un tercer Estado no parte, de los actos que suponen el ejercicio de poder público en otro Estado resultado de su consentimiento, invitación o aquiescencia del gobierno local y de los actos de poder y control físico de sus agentes sobre personas fuera de su territorio. El segundo motivo de aplicación extraterritorial es cuando un Estado parte ejerce el control efectivo sobre un territorio como consecuencia de una acción militar ${ }^{43}$.

\section{LOS EFECTOS DE LOS TRATADOS DE PROTECCIÓN DE INTERESES GENERALES EN LA EVOLUCIÓN Y FLEXIBILIZACIÓN DEL DERECHO DE LOS TRATADOS}

Además de las características examinadas anteriormente, los tratados objeto de estudio presentan también algunos rasgos adicionales que no siempre comparten con otros tratados multilaterales y que conducen a la flexibilización ${ }^{44}$, la interpretación progresiva y, en suma, a la evolución del Derecho de los tratados. Dichos rasgos son: la democratización de su proceso de elaboración y adopción, la erosión del papel del consentimiento y el incremento de la capacidad de adaptación al cambio a través de la creación y funcionamiento en el marco de regímenes internacionales generales. Varios motivos explican

\footnotetext{
nión consultiva de la CIJ sobre las consecuencias jurídicas de la construcción de un muro en el territorio palestino ocupado, de 9 de julio de 2004 (ICJ Reports 2004), párrs. 108-113. Véase Milanovic, M., Extraterritorial Application of Human Rigths Treaties: Law, Principles, and Policy, Oxford, Oxford University Press, 2011. Sobre la aplicación extraterritorial de los derechos económicos sociales y culturales, véase Langford, M., Wandenhole, W., Scheinum, M. y van Genugten, W. (eds.), Global Justice, State Duties. The Extraterritorial Scope of Economic Social and Cultural Rights in International Law, Cambridge, CUP, 2013; también los Principios de Maastricht sobre las obligaciones extraterritoriales de los Estados en el área de los derechos económicos, sociales y culturales, adoptados el 28 de septiembre de 2011 (versión final de 29 de febrero de 2012).

43 Asunto Al-Skeini y otros c. Reino Unido, Sentencia de la Gran Sala de 7 de julio de 2011, párrs. 131-142. Véase Domínguez Matés, R., «Las fronteras del orden público europeo en materia de derechos humanos: la aplicación extraterritorial del Convenio Europeo de Derechos Humanos», en FERNÁNDEZ SÁnchez, P. A. (ed.), La obra jurídica del Consejo de Europa (en conmemoración del 60 aniversario del Consejo de Europa), Sevilla, Gandulfo, 2010, pp. 799-818; y MorgadeS GIL, S., «La aplicación extraterritorial del Convenio Europeo de Derechos Humanos y Libertades Fundamentales: el concepto de jurisdicción en perspectiva cosmopolita», en García SEguRA, C. (dir.), La tensión cosmopolita. Avances y límites en la institucionalización del cosmopolitismo, Madrid, Tecnos, 2016, pp. 149-192.

${ }_{44}$ Un enfoque diferente pero muy sugerente es el de MARTín RoDríGuEz, P. J., Flexibilidad y tratados internacionales, Madrid, Tecnos, 2003, en el que se reivindica la flexibilidad de los tratados como una «categoría jurídica autónoma».
} 
la presencia de estos elementos. En primer lugar, razones de legitimidad, que aconsejan la democratización del proceso de elaboración y adopción de los tratados objeto de estudio. En segundo lugar, motivos de eficacia, que exigen la flexibilización del consentimiento de los Estados parte. Y, en tercer lugar, la necesidad de una gestión activa de los intereses generales de la comunidad internacional, que requiere de una significativa capacidad de adaptación al cambio debido a la evolución de los problemas a los que pretenden hacer frente, a la evolución en la propia calificación de los intereses generales o a las expectativas variables de los miembros de la comunidad internacional.

\subsection{La democratización en el proceso de elaboración y adopción de los tratados}

Como se ha mencionado, la búsqueda de legitimidad en su consideración de instrumentos de protección de los intereses generales de la comunidad internacional ha promovido una progresiva democratización en el proceso de elaboración y adopción de los tratados objeto de estudio. En este sentido, estos son habitualmente negociados y adoptados en el marco de foros más o menos institucionalizados abiertos a la participación de todos los Estados, como organizaciones internacionales, conferencias internacionales convocadas por estas o incluso en el seno de los órganos de gestión de los propios tratados. La negociación de los tratados en dichos foros colectivos favorece la deliberación racional y una mejor identificación, interpretación y delimitación de los intereses generales de la comunidad internacional, conllevando muy frecuentemente que en la práctica sea la propia organización u órgano el que elija las materias a tratar y ejerza la iniciativa de formular los proyectos de tratados. Dichos proyectos se elaboran generalmente en el marco de órganos técnicos independientes, a partir de estudios y memorandos previos, y constituyen el punto de partida de la negociación por parte de los representantes de los Estados en la organización u órgano de gestión, o de las delegaciones de los mismos en las conferencias internacionales convocadas por estas. Este funcionamiento propicia que, a pesar de que los Estados sigan negociando en clave de interés particular, la propia organización u órgano y los trabajos que en ella se elaboran responden a presupuestos fácticos, técnicos y teleológicos que están más vinculados a la protección del interés general de la comunidad internacional. Ello condiciona y limita inevitablemente todo el proceso de negociación, en la medida en que las observaciones, enmiendas o reservas de los representantes de los Estados se plantean en relación con dichos textos de referencia. Igualmente, la negociación se lleva a cabo normalmente mediante la técnica del consenso, una técnica de adopción de decisiones que evita que la voluntad o los intereses de uno o varios Estados se impongan en relación a los de otros.

El fenómeno de democratización alcanza también a las fases de adopción y autenticación del tratado. Mientras que los tratados multilaterales clásicos suelen adoptarse por unanimidad o consentimiento de todos los Estados par- 
ticipantes, en los tratados de protección de intereses generales es frecuente que su adopción responda a reglas de mayoría o mayoría cualificada, impidiendo que el interés particular de uno o varios Estados bloquee la adopción de un tratado que en general sea percibido como favorable a dichos intereses. En este sentido, la regla general recogida en la CVDT establece que será suficiente el voto afirmativo de dos tercios de los Estados presentes y votantes (art. 9). Una vez adoptado el texto, el proceso de autenticación viene condicionado también por el contexto institucional en el que dichos tratados son elaborados. Así, tanto la firma como otros medios tradicionales de autenticación regulados en el art. 10 de la CVDT han perdido uso en beneficio de otros procedimientos como la inclusión del texto del tratado en el Acta Final de la Conferencia (posibilidad también prevista en el art. 10 CVDT); su inclusión en una resolución del órgano de la organización internacional en cuyo seno se ha elaborado el tratado; y la firma del texto del tratado por el presidente del órgano o secretario general de la Organización (posibilidades que se desprenden del art. 5 CVDT) ${ }^{45}$. En la práctica más reciente es frecuente también la aprobación de algunos tratados por el órgano plenario de gestión del tratado marco (la Conferencia de las Partes), como es el caso del Protocolo de Kyoto sobre el cambio climático y del Acuerdo de París sobre el cambio climático ${ }^{46}$. Dichas modalidades de adopción y autenticación de los tratados encajan mejor en el dinamismo, eficacia y capacidad de respuesta que exige la protección de los intereses generales de la comunidad internacional.

A lo largo de todo el proceso, este método colectivo de elaboración y adopción favorece la participación de todos los Estados e, incluso, en algunos casos y cada vez con mayor frecuencia y amplitud, la participación de otros miembros de la comunidad internacional como es la sociedad civil organizada. Así, a través de diversas modalidades, como, por ejemplo, el otorgamiento de estatutos de observador, las organizaciones no gubernamentales tienen cabida en la negociación de los tratados, haciendo posible expresar sus posiciones y que estas sean reflejadas en los documentos de trabajo.

\subsection{La erosión del papel del consentimiento}

En el Derecho internacional clásico, el consentimiento de los Estados constituía la condición y el requisito para la creación de obligaciones en el marco de un ordenamiento jurídico internacional caracterizado por el voluntarismo y el relativismo. En el Derecho internacional contemporáneo, aunque el consentimiento de los Estados sigue desempeñando un papel primordial,

45 Y que fueron identificadas por Alejandro Rodríguez Carrión en RodRíguez CARRIón, A. J., op. cit., nota 6, pp. 334-335.

${ }_{46}$ El Protocolo de Kyoto fue aprobado por la decisión 1/CP.3, de 11 de diciembre de 1997, de la COP de la Convención marco de las Naciones Unidas sobre cambio climático de 1992 (BOE núm. 3 , de 8 de febrero de 2005). El Acuerdo de París, por su parte, ha sido aprobado por la decisión 1/CP.21, de 12 de diciembre de 2015, de dicha COP (su texto ha sido publicado en DO L núm. 282, de 19 de octubre de 2016). 
este ya no explica el fundamento último de la obligatoriedad de las normas jurídicas internacionales ni, en particular, la de algunas de sus clases. Así, la exigencia de eficacia en la regulación y protección de los intereses generales de la comunidad internacional ha dado lugar, en los tratados que regulan tales intereses, a ejemplos de flexibilización del consentimiento de los Estados que, en el fondo, están erosionando el papel que el mismo desempeña en el Derecho de los tratados y aun en el ordenamiento jurídico internacional.

La práctica internacional que permite ejemplificar la erosión del papel del consentimiento afecta a diversos aspectos del Derecho de los tratados: a la creación de normas, a la admisibilidad de reservas, a la interpretación, a la modificación del tratado y a la terminación, retirada y suspensión del mismo. En primer lugar, en materia de creación de normas, la flexibilización del consentimiento se evidencia en la introducción de procedimientos simplificados de adopción, modificación y enmienda de algunos anexos y apéndices a los tratados objeto de estudio y a sus protocolos, cuya entrada en vigor se predica para todos los Estados parte en el tratado aunque no hayan manifestado expresamente su consentimiento respecto de aquellos ${ }^{47}$.

En segundo lugar, la erosión del papel del consentimiento del Estado se pone de manifiesto también respecto a la admisibilidad o no de reservas a estos tratados. La tradicional tensión entre integridad y universalidad del tratado, que aconsejan respectivamente limitar o permitir la presentación de reservas, resulta exacerbada en los tratados de protección de los intereses generales de la comunidad internacional. Por ello, si bien en materia de reservas rige especialmente el criterio de la compatibilidad con el objeto y fin de la norma, tal y como fue apuntado por la CIJ en su Opinión consultiva relativa a las reservas al Convenio para la prevención y sanción del delito de genocidio ${ }^{48}$ y codificado en los arts. 19 a 23 de la CVDT, tales normas tienen carácter subsidiario ya que son aplicables solo si el tratado no prevé regulación expresa. Por ello, para hacer frente a los graves inconvenientes que generan las reservas en los tratados de protección de intereses generales (erosionan su integridad y fomentan el relativismo), en la práctica de las últimas décadas es frecuente que se limite o se prohíba de forma expresa la formulación

47 Es el caso, por ejemplo, del Convenio de Viena para la protección de la Capa de Ozono, firmado el 22 de marzo de 1985, BOE núm. 275, de 16 de noviembre de 1988, cuyo articulado desdobla el régimen de adopción de enmiendas, según se trate de enmiendas referidas al Convenio o a los protocolos (art. 9) o a los anexos (art. 10), preveyendo un sistema más simple y acelerado en este segundo caso, al tratarse de enmiendas que no afectan al núcleo esencial de la regulación. Un ámbito en el que se manifiesta especialmente la erosión del consentimiento en la creación de normas es en el de la protección del medio ambiente: SHIBATA, A., «International Environmental Lawmaking in the first decade of the Twenty-first Century: The Form and Process", Japanese Yearbook of International Law, vol. 54, 2011, pp. 28-61, en especial, pp. 44-59, explica la erosión del consentimiento como el resultado de un proceso interactivo en el que es imperante la participación en él. También BRunNÉE, J., «Reweaving the Fabril of International Law? Patterns of Consent in Environmental Frameworks Agreements», en Wolfrum, R. y RöBen, V. (eds.), Developments in International Law in Treaty Making, Berlín, Springer, 2005, pp. 101-126.

48 Reservas a la Convención sobre la prevención y la represión del crimen de genocidio, Opinión consultiva de 28 de mayo de 1951 (CIJ Recueil, 1951), p. 22. 
de reservas ${ }^{49}$. Es el caso, por ejemplo, de la Convención Marco de las Naciones Unidas sobre el cambio climático ${ }^{50}$; de la Convención suplementaria sobre la abolición de la esclavitud, la trata de esclavos y las instituciones y prácticas análogas a la esclavitud ${ }^{51}$; o de algunos convenios internacionales adoptados por la Organización Internacional del Trabajo (OIT), los cuales incorporan distintas medidas de flexibilización pero no admiten la formulación de reservas ${ }^{52}$. También pueden identificarse particularidades en relación con los mecanismos de control de la aplicación del régimen de las reservas. Así, mientras que el mecanismo tradicional previsto en la CVDT se basa en el consentimiento individual de los Estados, en la medida en que una reserva es válida si es aceptada por algún otro Estado, en los tratados de protección de intereses generales y, en particular, en los tratados de derechos humanos en particular, es habitual que se introduzcan otros sistemas de control alternativos por parte de órganos de supervisión previstos en los propios tratados que no representan la voluntad y los intereses individuales de los Estados, sino los intereses generales de la comunidad internacional en su conjunto.

En tercer lugar, dicha erosión resulta evidente en el ámbito de la interpretación. Si bien existen diversos métodos de interpretación de un tratado internacional, la singularidad de los tratados objeto de estudio radica en una preferencia por los métodos de interpretación que tienen en cuenta el objeto y fin de las normas y obligaciones previstas en el tratado (interpretación teleológica) y el contexto jurídico en el que se estas se enmarcan (interpretación sistémica) ${ }^{53}$. La naturaleza normativa de este tipo de tratados y su voluntad de establecer normas de conducta generales para los Estados da pie a una interpretación de sus obligaciones que persigue desentrañar el régimen establecido por el tratado y las circunstancias materiales y jurídicas en las que debe ser aplicado, desvinculándolo tanto del contexto histórico en el que fueron concluidos como de la voluntad expresada en su momento por los Estados negociadores. El juez de la CIJ, M. Álvarez, hizo referencia a ello

49 Véase el Décimo informe sobre las reservas a los tratados, preparado por el Sr. Alain Pellet, Relator especial, de 1 de junio de 2005 (A/CN.4/558), p. 13, nota 63.

${ }^{50}$ Convención marco de las Naciones Unidas sobre el cambio climático, BOE núm. 27, de 1 de febrero de 1994, art. 24.

51 Convención suplementaria sobre la abolición de la esclavitud, la trata de esclavos y las instituciones y prácticas análogas a la esclavitud, hecha en Ginebra el 7 de septiembre de 1956, BOE núm. 311, de 29 de diciembre de 1967, art. 9.

52 Por ejemplo, cláusulas con normas modificadas para los países que mencionan o la división del convenio en partes, algunas de cuyas obligaciones pueden aceptarse en el momento de la ratificación, lo que permite la extensión gradual de las obligaciones según evolucione la legislación social y los medios de cumplimiento de la misma. Véase el Manual sobre procedimientos en materia de convenios y recomendaciones internacionales del trabajo, Departamento de normas internacionales del trabajo, Oficina Internacional del Trabajo, Ginebra, Rev. 2006, pp. 6 y 18, párr. 25.

53 BRÖlman, C., «Law-Making Treaties: Form and Function in International Law», NJIL, 2005, núm. 74, pp. 383-404, p. 393. En un sentido parecido, Lucía Millán Moro destaca la exigencia de reglas de interpretación específicas, adecuadas a sus finalidades y a sus obligaciones de carácter objetivo, para los tratados de protección de los derechos humanos, Millán Moro, L., «La interpretación de los tratados», CEBDI, vol. XI/XII, 2007-2008, pp. 451-518, en pp. 465-467; también DuPUY, P. M., «Evolutionary Interpretation of Treaties: Between Memory and Prophecy», en CANNIzZARo, E. (ed.), The Law of Treaties Beyond the Vienna Convention, Oxford, Oxford University Press, 2011, pp. 123-137. 
en su voto particular a la citada Opinión consultiva relativa a las reservas al Convenio para la prevención y sanción del delito de genocidio cuando afirmó que este tipo de convenciones «no deben ser interpretadas en relación con los trabajos preparatorios que las preceden; estas difieren de estos trabajos $\mathrm{y}$ adquieren vida propia [...] deben ser interpretadas sin tener en cuenta el pasado, y solamente en relación al futuro" ${ }^{54}$. Ello se traduce en un menor recurso durante la interpretación a los acuerdos de las partes durante la celebración del mismo o a sus trabajos preparatorios, y a una mayor atención, por ejemplo, a «toda forma pertinente de derecho internacional aplicable en las relaciones entre las partes» [art. 31.3.c) de la CVDT].

En cuarto lugar, y en la medida en que los tratados de protección de intereses generales suelen incorporar obligaciones de estructura integral, existen limitaciones a la posibilidad de que los Estados parte en los mismos acuerden la modificación del tratado por medio de acuerdos interestatales. Si bien la CVDT admite la celebración tales acuerdos entre las partes con el objeto de modificar inter se las obligaciones de un tratado, esta posibilidad se encuentra limitada a que dichos acuerdos no resulten incompatibles con el objeto y fin del tratado [art. 41.1.b)ii)]. Y, tal y como afirma el Informe sobre la Fragmentación del Derecho internacional, son sobre todo los acuerdos inter se que modifican obligaciones no recíprocas, de naturaleza interdependiente o integral, los que con mayor probabilidad afectan al objeto y fin del tratado ${ }^{55}$.

Finalmente, en quinto y último lugar, la flexibilización del consentimiento se manifiesta también respecto a la denuncia o retiro de una parte y respecto de la suspensión y la terminación de tales tratados. Por un lado, la denuncia o retiro de una parte solo es posible conforme a las disposiciones del tratado o, en cualquier momento, por el consentimiento de todas las demás partes (art. 54 CVDT). La regla general, por tanto, es que si el tratado no lo regula, un tratado no podrá ser objeto de denuncia o de retiro por un Estado parte a menos que conste que fue intención de las partes admitir tal posibilidad [art. 56.1.a) CVDT] o que el derecho de denuncia o retiro pueda inferirse de la naturaleza del tratado [art. 56.1.b)]. En la práctica convencional, la mayoría de los tratados de protección de intereses generales no regula de forma expresa su denuncia o retiro. Esta práctica ha suscitado el debate de si es posible retirarse del régimen de tales tratados y, muy especialmente, de los tratados de protección de los derechos humanos ${ }^{56}$. Para algunos autores, de

54 Reservas a la Convención sobre la prevención y la represión del crimen de genocidio, op. cit., nota 49, Opinión Disidente de M. Álvarez, p. 53 (la traducción es nuestra). También el asunto Mathews c. Reino Unido, Sentencia de 18 de febrero de 1999 (asunto núm. 24833/94), en que el TEDH afirmo que «los tratados de interés colectivo son instrumentos vivos que deben ser interpretados a la luz de sus condiciones actuales» (párr. 39).

55 Fragmentación del Derecho internacional, op. cit., nota 38, p. 184, párr. 313. En el mismo sentido, Informe de la Comisión de Derecho Internacional sobre la labor realizada en su 56 periodo de sesiones, de 3 de mayo a 4 de junio y de 5 de julio a 6 de agosto de 2004, Asamblea General. Documentos oficiales. 59 periodo de sesiones, Suplemento núm. 10 (A/59/10), p. 329, párr. 340.

56 Véase, entre otros, Tyagi, Y., "The Denunciation of Human Rights Treaties», BYIL, vol. 79, 2009, pp. 86-193; o KLEIN, E., «Denunciation of Human Rights Treaties and the Principle of Reciprocity», en 
la especial naturaleza de los mismos, en los que no puede hablarse de intereses individuales de los Estados sino únicamente de intereses de la comunidad internacional en su conjunto, podría inferirse que tal posibilidad no resulta admisible ${ }^{57}$; otros aconsejan prudencia y no identificar necesariamente la ausencia de una cláusula de denuncia en el tratado como exclusión de tal posibilidad, interpretando dicho silencio simplemente como falta de acuerdo al respecto ${ }^{58}$. La práctica muestra algunos ejemplos de denuncia o de retiro de Estados parte de tratados de este tipo ${ }^{59}$. En algunos de estos casos, la explicación de dichas denuncias o retiro tiene más que ver con razones coyunturales de política interna que de oposición al objeto y fin, al interés público global protegido. Por ello, en la práctica más reciente se han incorporado algunas limitaciones a dicha posibilidad para intentar hacer frente a la oposición coyuntural de un determinado gobierno en un momento dado ${ }^{60}$.

La especial naturaleza de este tipo de tratados, así como las obligaciones de estructura integral que suelen contener afectan también a las reglas aplicables a su terminación o suspensión como consecuencia de una violación grave del mismo (art. 60 CVDT). La violación grave de un tratado multilateral con obligaciones de estructura bilateral u obligaciones interdependientes únicamente faculta a las otras partes a dar por terminado, o suspender la aplicación del tratado (con una gama más amplia de opciones en este último caso), en las relaciones con el Estado autor de la violación, o entre todas ellas, si proceden solidariamente por acuerdo unánime (art. 60.2) ${ }^{61}$. Ahora bien, estas reglas no se aplican respecto a las disposiciones relativas a la protección de la persona humana contenidas en los tratados de carácter humanitario,

Fastenrath, U., Geiger, R., Khan, D.-E., Paulus, A., von Schorlemer, S. y Vedder, Ch., From Bilateralism to Community Interest: Essays in Honor of Judge Bruno Simma, Oxford, Oxford University Press, 2011, pp. 477-487, p. 477.

57 Simma, B., "How distinctive are treaties representing collective interests? The case of Human Rights Treaties», en Gowlland-DebBas, V. (ed.), Multilateral Treaty-Making. The Current Status of Challenges to and Reforms Needed in the International Legislative Process, papers presented in Geneva, Switzerland, May 16, 1998, La Haya, Martinus Nijhoff Publishers, 2000, pp. 83-87, p. 86.

58 Conde Pérez, E., La denuncia de los tratados. Régimen en la Convención de Viena sobre el derecho de los tratados de 1969 y práctica estatal, Madrid, Congreso de los Diputados, 2007, p. 57.

59 El anuncio de Corea del Norte de abandonar el Pacto de Derechos Civiles y Políticos (BOE núm. 103, de 30 de abril de 1977) en 1997 y el Tratado sobre la no proliferación de las armas nucleares (BOE núm. 313, de 31 de diciembre de 1987) en 2013. En este último caso, el Consejo de Seguridad, en su Resolución 2094 (2013), de 7 de marzo, llegó a exigir que Corea del Norte se retractara en su decisión. Las decisiones de Canadá de retirarse del Protocolo de Kyoto en 2011 y de la Convención de las Naciones Unidas de Lucha contra la Desertificación (BOE núm. 36, de 11 de febrero de 1997) en 2013. Las notificaciones de retiro de Sudáfrica, de Burundi, Gambia y otros países africanos en los últimos meses de 2016 del Estatuto de la Corte Penal Internacional (BOE núm. 126, de 27 de mayo de 2002).

${ }^{60}$ Un buen ejemplo es el Acuerdo de París sobre el cambio climático de 2015, cuyo art. 28 exige que hayan transcurrido tres años desde la fecha de entrada en vigor para esa parte, para poder denunciar el Acuerdo (art. 28.1). Además, los efectos de la denuncia se producirán al cabo de un año desde la fecha de la notificación (art. 28.2). Estas limitaciones tienen por objeto hacer más difícil que un determinado gobierno, en una sola legislatura de cuatro años, pueda convertir a un Estado parte en Estado no parte.

61 Simma, B., «Reflections on Article 60 of the Vienna Convention on the Law of the Treaties and its Background in International Law», OZöR, 1970, pp. 5-83. 
en particular a las disposiciones que prohíben toda forma de represalias con respecto a las personas protegidas por tales tratados (art. 60.5). En este sentido y como excepción a la regla general establecida en los párrs. 1 a 3 del mismo artículo, la violación, aunque sea grave, de una disposición relativa a la protección de la persona humana por un Estado no constituye para el resto de partes en el tratado, ni una causa de suspensión, terminación o retirada del mismo, ni, en general, una justificación para su incumplimiento, ni tan siquiera vis-à-vis frente a la parte que ha incumplido ${ }^{62}$. En la actualidad, la especial naturaleza de los tratados de protección de intereses generales y de las obligaciones de estructura integral en ellos contenidas hace que la excepción del art. 60.5 sea insuficiente. En otros términos, «estas reglas del art. 60 tampoco deberían aplicarse a las disposiciones que crean obligaciones de estructura integral que tienen por objeto la protección de intereses generales de la comunidad internacional» ${ }^{63}$.

En la misma línea, dicho tipo de tratados no se terminan ni suspenden automáticamente como consecuencia de la irrupción de un conflicto armado entre todos o algunos de sus Estados parte. Así se establece en el Proyecto de artículos sobre los efectos de los conflictos armados en los tratados aprobado en $2011^{64}$. De acuerdo con el mismo, dichos tratados no se terminan ni se suspenden automáticamente en tiempo de conflicto armado; por el contrario, se establece la presunción de que los mismos continúan siendo aplicables ${ }^{65}$.

\subsection{La capacidad de adaptación al cambio a través de la creación de regímenes internacionales generales}

Los tratados de protección de intereses generales suelen operar y producir efectos en el marco de regímenes internacionales generales en los que están demostrando una gran capacidad de adaptación al cambio y a las nuevas necesidades que presentan la protección y regulación jurídica del interés pú-

62 Anuario de la Comisión de Derecho Internacional, vol. II, 1957, op. cit., nota 13, p. 58, párr. 125.

63 Casanovas, O. y Rodrigo, A. J., op. cit., nota 17, p. 112. La necesidad de articular alternativas a la terminación o a la suspensión del tratado ante un incumplimiento de obligaciones que protegen intereses colectivos permitiría explicar, por ejemplo, en el ámbito regional, el mecanismo previsto en el art. 7 del Tratado de la Unión Europea (TUE), DO C núm. 326, de 26 de octubre de 2012, para violaciones graves y persistentes, por parte de un Estado miembro, de los valores recogidos en el art. 2 TUE (la paz, sus valores, el bienestar de los pueblos, la dignidad humana, los derechos humanos, la libertad, la igualdad, la justicia, la democracia o el estado de derecho, entre otros). Ante la constatación de la violación por parte del Consejo Europeo, por unanimidad y a propuesta de un tercio de los Estados miembros o de la Comisión y previa aprobación del Parlamento Europeo, el Consejo podrá decidir, por mayoría cualificada, que se suspendan determinados derechos derivados de la aplicación de los Tratados al Estado miembro de que se trate, incluidos los derechos de voto de dicho Estado miembro en el Consejo; las obligaciones derivadas de los Tratados, por el contrario, continuarán siendo vinculantes para este.

${ }_{64}$ Resolución A/RES/66/99 de la Asamblea General, de 9 de diciembre de 2011, sobre los efectos de los conflictos armados en los tratados.

65 Los «tratados multilaterales normativos», los «tratados para la protección internacional de los derechos humanos» o los «tratados relativos a la protección internacional del medio ambiente» son, a título indicativo, tratados que «en razón de su materia, continúan aplicándose, en todo o en parte, durante un conflicto armado, letras $c$ ), f) y g) del anexo al proyecto, en relación con su art. 7». 
blico global. Esta capacidad de adaptación al cambio, así como la democratización en su proceso de negociación y adopción y la erosión del consentimiento, están contribuyendo a la evolución y flexibilización del Derecho de los tratados. El carácter evolutivo de los intereses protegidos y de las necesidades sociales exigen una gestión activa de los intereses generales de la comunidad internacional. Ese dinamismo resulta además potenciado, fortalecido y gestionado gracias a la aptitud de dichos tratados para crear o funcionar en el seno de regímenes o subregímenes internacionales de protección de intereses generales ${ }^{66}$.

Un régimen internacional general puede definirse un «conjunto de principios, normas y modalidades de aplicación que regulan intereses generales de la comunidad internacional» ${ }^{67}$. Estos regímenes que protegen intereses generales o recursos globales de la comunidad internacional se caracterizan por contener, junto con las normas primarias que regulan conductas, normas secundarias que regulan la identificación, creación y aplicación de las primeras, así como, en algunos casos, reglas secundarias que regulan de forma específica la responsabilidad por incumplimiento de las normas primarias del régimen o por daños derivados de las actividades en él reguladas.

Algunas de las normas secundarias regulan mecanismos de creación normativa de muy diverso orden que pueden dar como resultados normativos tratados, resoluciones de organizaciones internacionales o de órganos de gestión de tratados, declaraciones, guías directrices y códigos de conducta, en cuyo origen o elaboración participan no solamente los Estados sino también actores no estatales como las organizaciones no gubernamentales.

Por otra, existen también normas secundarias que establecen mecanismos particulares para la supervisión de la aplicación de las obligaciones. En el caso de los regímenes de protección del medio ambiente, se han desarrollado mecanismos de seguimiento y control integrales basados en incentivos y penalizaciones para promover el cumplimiento de las obligaciones. Así, algunos tratados multilaterales de protección del medio ambiente han dado lugar a los denominados «mecanismos para el examen del cumplimiento», que en muchos casos han dado lugar a la creación de mecanismos consultivos multilaterales con funciones de facilitación y control, a la vez que algunos tratados han incorporado una multiplicidad de instrumentos jurídicos para promover el cumplimiento de sus obligaciones a través de incentivos

66 Así, por ejemplo, el subrégimen de la Antártida, creado en torno al Tratado Antártico adoptado en Washington, el 1 de diciembre de 1959, BOE núm. 152, de 26 de junio de 1987, o bien del subrégimen internacional del ozono, integrado por el Convenio de Viena para la protección de la capa de ozono de 1985, BOE núm. 275, de 16 de noviembre de 1988; el Protocolo de Montreal relativo a las sustancias que agotan la capa de ozono de 1987, BOE núm. 65, de 17 de marzo de 1989; y las sucesivas resoluciones y decisiones de sus órganos de gestión, especialmente de la Conferencia y la Reunión de las partes.

67 Casanovas, O., "Aproximación a una teoría de los regímenes en Derecho internacional público», en Rodrigo, Á. J. y García, C. (eds.), op. cit., nota 35, pp. 41-60; también Remiro, A., «La noción de regímenes internacionales en el Derecho internacional público», en Rodrigo, Á. J. y García, C. (eds.), op. cit., nota 35 , pp. 167-176. 
económicos tanto positivos (incentivos fiscales, cupos negociables, ayuda financiera y subvenciones, etc.) como negativos (tasas, impuestos, supresión de subvenciones, etc.). Destaca que, en la práctica, se ha producido también una creciente participación de actores distintos de los propios Estados, como individuos, grupos de individuos u organizaciones no gubernamentales, en el seguimiento y control de la observancia de las obligaciones de dichos regímenes ${ }^{68}$. En este sentido, resulta habitual la designación de nacionales en calidad de observadores internacionales ${ }^{69}$, así como la concesión de estatutos de observador a organizaciones internacionales gubernamentales $\mathrm{u}$ organizaciones internacionales o nacionales no gubernamentales en el marco de conferencias internacionales ${ }^{70}$.

Finalmente, aunque tampoco es un fenómeno generalizado, en algunos regímenes internacionales generales han proliferado normas secundarias de aplicación que establecen reglas y mecanismos para exigir responsabilidad por la violación de las normas primarias o por los daños derivados de las actividades reguladas por el régimen. Algunos ejemplos se dan en el régimen internacional de la Antártida, del espacio ultraterrestre ${ }^{71}$ o del movimiento transfronterizo de desechos y su eliminación.

Frecuentemente, las especiales características de los tratados de protección de intereses generales que integran los regímenes internacionales generales les confieren a estos un carácter extraordinariamente dinámico y adaptable. Un buen ejemplo de ello son los creados por los tratados internacionales de protección del medio ambiente ${ }^{72}$. El dinamismo y capacidad de adaptación al cambio que estos presentan deriva de aspectos diversos como son la existencia de foros e instituciones que posibilitan una discusión y negociación continuada de los problemas ambientales y sus soluciones, la internalización de la función judicial dentro de los mismos ${ }^{73} \mathrm{y}$, sobre todo, su

68 Borràs Pentinat, S., «Los mecanismos de control de la aplicación y del cumplimiento de los tratados internacionales multilaterales de protección del medio ambiente», tesis doctoral (ISBN: 97884-691-06525/DL.T: 2223-2007) dirigida por el Dr. A. PigRAu SolÉ, Universitat Rovira i Virgili, 2007, p. 40; publicada parcialmente en la monografía El control internacional de los tratados multilaterales de protección del medio ambiente ¿Apariencias o realidades?, Valencia, Tirant lo Blanch, 2013.

69 Como los que pueden designar las Partes en el Tratado Antártico, hecho en Washington el 1 de diciembre de 1959, BOE núm. 152, de 26 de junio de 1987, art. 7.

70 La concesión de dicho estatuto de observador está previsto, por ejemplo, en la Convención sobre el comercio internacional de especies amenazadas de fauna y flora silvestres, hecha en Washington el 3 de marzo de 1973, BOE núm. 181, de 30 de julio de 1986, y BOE núm. 191, de 10 de agosto de 1991, párr. 7 del art. XI.

71 Este es el caso del Convenio sobre responsabilidad internacional por daños causados por objetos espaciales de 1972, BOE núm. 106, de 2 de mayo de 1980, en el que se regula la responsabilidad objetiva del Estado de lanzamiento por daños producidos en la superficie terrestre (art. II), la responsabilidad por culpa por daños fuera de la superficie terrestre (art. III) y los procedimientos y requisitos para obtener la reparación de los daños. Cfr. GuTIÉRREz EsPADA, C., La responsabilidad internacional por daños en el derecho del espacio, Murcia, Secretariado de Publicaciones, 1979.

72 Véase Elizalde Carranza, M. Á., Las medidas comerciales multilaterales para la protección del medio ambiente y el sistema multilateral del comercio, México D. F., Universidad Nacional Autónoma de México, 2008, pp. 27-28.

73 Sobre ello, véase GeHring, T., «International Environmental Regimes: Dynamic Sectoral Legal Systems», YIEL, vol. 1, 1990, pp. 35-56, en pp. 50-56. 
estructura. Dichos regímenes suelen estar formados, en primer lugar, por un tratado marco que identifica el problema ambiental esencial, establece unas obligaciones y principios básicos, y crea algunas instituciones «que permitan la continuidad del proceso negociador y del proceso normativo para desarrollar el régimen y adaptarlo a las circunstancias cambiantes»; en segundo término, por protocolos diversos que establecen obligaciones específicas para los Estados; en tercer lugar, por anexos técnicos que desarrollan y precisan obligaciones, conceptos, bienes protegidos o mecanismos de solución de controversias; y, finalmente, por resoluciones de los órganos de gestión de tratados que «desarrollan, completan, precisan y adaptan los textos primarios a las nuevas necesidades» ${ }^{74}$.

\section{CONSIDERACIONES FINALES}

El reconocimiento, la protección y la regulación jurídica de los intereses generales de la comunidad internacional han generado importantes novedades cualitativas en la caja de herramientas comunitarias del Derecho internacional, entre otras, las normas de interés público y las obligaciones de estructura integral que se derivan de ellas. Los tratados de protección de intereses generales son una de esas novedades cualitativas que, junto con otras ya apuntadas, están contribuyendo a transformar el ordenamiento jurídico internacional en un auténtico Derecho internacional público. Estos tratados se pueden definir como aquellos que tienen por objeto la regulación y protección de intereses generales de la comunidad internacional mediante la creación de algunas normas de interés público de las que se derivan obligaciones de estructura integral que tienen una vocación universal.

A pesar de las limitaciones que plantean algunos de los principios básicos del Derecho de los tratados, los tratados de protección de intereses generales son hoy el mejor instrumento jurídico disponible para la creación de tales normas y obligaciones y, por tanto, para la protección del interés público global. La morfología de este tipo de tratados está caracterizada por tres rasgos: por su objeto y fin, la protección de los intereses generales; por la estructura integral de las obligaciones que se derivan de las normas de interés público en ellas contenidas; y por la vocación de universalidad tanto del propio tratado como, en especial, de sus normas de interés público.

La protección del interés público global exige hacer frente a importantes retos políticos (como la legitimidad, inclusividad y eficacia) y jurídicos. Las respuestas y soluciones incorporadas en los tratados de protección de intereses generales buscan satisfacer nuevas necesidades y resolver nuevos tipos de problemas. Sus efectos no se limitan a la gestión activa de tales problemas o intereses públicos globales sino que están contribuyendo a la evolución y flexibilización del Derecho de los tratados. Algunos de estos efectos

74 Casanovas, O. y Rodrigo, Á., op. cit., nota 17, p. 383. 
son la democratización de su proceso de elaboración y adopción, la erosión del papel del consentimiento y el incremento de la capacidad de adaptación al cambio a través de la creación o funcionamiento en el marco de regímenes internacionales generales.

Además, desde el punto de vista de la técnica jurídica, los tratados de protección de intereses generales son magníficas herramientas para la innovación jurídica ya que intentan dar respuesta a complejas cuestiones de distinta naturaleza que aparecen vinculadas a la protección del interés general concreto que regulan. Son, sin duda, uno de los ámbitos más fértiles de experimentación jurídica que existen hoy en el ordenamiento jurídico internacional.

\section{RESUMEN}

\section{EL CONCEPTO Y EFECTOS DE LOS TRATADOS DE PROTECCIÓN DE LOS INTERESES GENERALES DE LA COMUNIDAD INTERNACIONAL}

El presente trabajo tiene como objeto examinar uno de los instrumentos más idóneos para la protección del interés público global: los tratados de protección de intereses generales de la comunidad internacional. Para ello, en primer lugar, se define dicho tipo de tratados. En segundo lugar, se identifican y analizan sus principales características: la protección de intereses generales de la comunidad internacional como su objeto y fin; la estructura integral de algunas de sus obligaciones; y su vocación de universalidad. Y, en tercer lugar, se examinan algunas de las consecuencias que dichos tratados tienen en la evolución y flexibilización del Derecho de los tratados: en particular, la democratización en el proceso de elaboración y adopción de tratados; la erosión del papel del consentimiento; y su capacidad de adaptación al cambio a través de la creación de regímenes internacionales generales.

Palabras clave: tratados multilaterales, protección de intereses generales, Derecho de los tratados, interés público global.

\section{ABSTRACT \\ THE CONCEPT AND EFFECTS OF TREATIES FOR THE PROTECTION OF GENERAL INTERESTS OF THE INTERNATIONAL COMMUNITY}

The aim of this work is to examine one of the most suitable instruments for the protection of the global public interest: treaties for the protection of general interests of the international community. Firstly, the work defines this type of treaties. Secondly, it identifies and analyses their main characteristics: the protection of general interests as its object and purpose; the integral structure of some of its obligations; and its intended universal scope. And, thirdly, this work examines some of their consequences for the evolution and adaptation of the Law of treaties: in particular, the democratization in the process of drafting and adopting treaties; the erosion of the role of consent; and their ability to adapt to change through the creation of general international regimes.

Keywords: multilateral treaties, protection of general interests, Law of treaties, global public interest. 